\title{
Confidentiality: \\ what everyone should know, or, rather, shouldn't ...
}

\author{
'Three can keep a secret, if two of them \\ are dead.' \\ (Benjamin Franklin)
}

'Whoever wishes to keep a secret must hide the fact that he possesses one.' (Johann Wolfgang von Goethe)

'If you reveal your secrets to the wind you should not blame the wind for revealing them to the trees.'

(Kahlil Gibran)

Our village postman used to start a rumour at the first house of his delivery and see if he could beat the rumour to the end of his round. Medical gossip had a special cachet that proved unbeatable. One day it all went wrong when a rumour created by his imagination coincided with fact: not only was this unfortunate for the victim, but the only apparent and plausible source was the GP surgery. For us, the matter was quickly cleared up by a disclosure of the real explanation, an unfortunate coincidence, but the damage was done; a patient was badly harmed and it could not be undone. Witnessing damage like that reinforces the importance of medical confidentiality. While in the past such an event could only happen in a rural community, the advent of electronic storage and transfer of huge amounts of information, and the ability to target specific recipients has resulted in a global village, with village problems and issues; this is a concept barely grasped by either the public or our profession.

Since the NHS began until recently my home served as the village surgery. Consultations were conducted by my grandfather, my father, and latterly by me in the utmost confidence. Any information would only be disclosed in the interest of the patient. Information could be documented fully, partially, or exceptionally never recorded. Information remained where it belonged, physically confined in a little room. It never went anywhere else, unless there was a clear reason for disclosure which was in the patient's interest (for example in a referral letter) or rarely in the public interest. The purpose of sharing this information was equally constrained; never an end in itself, but an attempt to reach a shared understanding of the best way forward to resolve a clinical problem. Computers give us the opportunity to share huge amounts of information impossible to contemplate in a paper system; in essence are we on the way to delivering a 200-page referral letter?

While we were an early convert to the benefits of computers within our practice, I have mistrusted the use of externally held databases ever since the first regional database in our area was of schizophrenics. In a nanosecond the delusions with which so many had been troubled, even compulsorily detained, became fact. In Scotland, there already is a national database, the Electronic Care Summary, stored in a single computer (copied instantly to a second information treasure trove at a backup site). This contains a considerable amount of patient information, demographic data, previous medication, and allergies, although far short of what is envisaged for the future in England, a national repository complete with all medical records for primary and secondary care to which there are tens of thousands of keys.

Government made the decision to obtain consent to transfer this information from the GP surgery to a central database by a combination of a publicity campaign and mailshot. We now know that many individuals received no notification that their information was to be transferred to an Emergency Care Summary (ECS). The reason for this is unclear, but presumably for reasons of cost, the missive was sent as 'junk mail' to the occupier, and not to a named individual. Perhaps a decision was made on behalf of whole families by a single member; many households have blocked junk mail. The Royal Mail also limits the amount of junk mail that is delivered to each household. This vastly reduced the effectiveness of the communication. The authorities involved are reluctant to divulge how much they know about this failure to adequately inform each patient. When questioned, few professional colleagues had received such information, and several straw polls by other practices throughout Scotland have revealed a very poor understanding of what has actually been done with this personal medical information.

The vast majority of GPs assumed informed consent. They accepted the state's view that a 'opt in' consent at the time of consultation, for example at an accident and emergency department (A\&E), is sufficient safeguard to transmit these details to a central database. The use of the ECS is low, and information is copied and shared with a third party with only a remote possibility of this information being useful to an individual patient. The most effective link of the audit trail (the practice that provided the information) can be over-ridden because the inquiring clinician can tick a box stating that the GP will receive no notification of this information request.

Our practice looked at what our responsibilities should be. The GMC states: 'If you are asked to provide information about patients you must: inform patients about the disclosure, or check that they have already received information about it ... seek patients' express consent to disclosure of information, where identifiable data is needed for any purpose other than the provision of care or for clinical audit." The Scottish Consumer Council has as their first recommendation that 'NHS Scotland should adopt a strategic plan for informing members of the public of its plans for electronic storing and sharing of personal health information." ${ }^{2}$ The Royal College of GPs' Ethics Committee recommends that '... patients should have the right to 'opt in' thereby providing explicit consent - to the sharing of their medical information on the NHS Care Record. ${ }^{3}$ It is not clear whether this is opting in to allow GPs to transfer information, or opting in to consent to disclosure at an 'appropriate' time; 
presumably at a time of acute illness or distress.

There does appear to be a case that for the ECS there has been no informed consent. Many households, and many more individuals, did not receive this important information. The protagonists say that in an emergency, essential information may not be available. In 30 years of clinical practice, including regular A\&E sessions and thousands of temporary residents, I have found such a circumstance to be extremely rare. In the event the patient is unconscious, is it not possible that the patient may be incorrectly identified? How big a mistake could that cause by using the right information for the wrong patient? Systems exist to deal with the uncertainties of inadequate clinical data. There is, arguably, no need to risk the confidentiality of the majority for a few patients with specific conditions. Furthermore, the risks of nondisclosure are the patient's not ours. While, as clinicians, we can all see the convenience of having all the clinical information laid before us, perhaps we should ask ourselves three questions:

- Has not having instant access to computerised information led to an adverse outcome?

- Will sharing this patient's information improve his outcome?

- Will this information be accessible only on a 'need-to-know' basis?

There is also the impression that the information will be accurate. Much of what we write in general practice is supposition, conjecture, subjective not objective. A note may simply be a milestone in a longstanding process of understanding something very complex and difficult. If you know neither the writer nor the subject, it may obfuscate more than illuminate. This obsession with information is only part of a deeper malaise within the profession where the process of information gathering becomes more important than the outcome of truly understanding what is going on.

It seems possible that this system is not being introduced for the real clinical needs of the patient. Could it be for the convenience or peace of mind of managers or politicians? Knowledge is power after all. In the English system, sealed and locked data will be unavailable to some clinicians involved with clinical care but civil servants and researchers are alleged to have access! Managers may decide they need to know; where does this end? Health visitors? Social Work? Police? Insurance companies? Banks?

In agreeing to divulge this practice-based information I am sure my colleagues have assumed beneficence; that this is done with the best intentions. However beneficence (the intent) does not guarantee a beneficial result.

Our practice took the view that properly informed consent had not been obtained. We undertook to write to every patient personally, explaining the nature of disclosure to which it was assumed they had already consented. At the end of the day we had 350 opt outs for a list of approximately 1800 patients. This constitutes over onethird of the total opt outs for the whole of Scotland. Admittedly we gave a rather unbalanced view in our letter because it was to balance information contained in leaflets that we assumed had already been delivered.

Many of the people who choose to opt out are well-educated, professional people including those in medical and nursing roles who will be acutely aware of the significance of this information at each and every point in the journey of care. The MDU advice is now 'In the light of the GMC's statement above, GPs are advised to consider a number of things. They will need, for example, to satisfy themselves that the $\mathrm{CfH}$ publicity campaign has indeed reached all their patients, that all their patients have read and understood the leaflets...'4

Until recently I had been a little uncomfortable with what appeared to be our inadvertent misrepresentation. The loss of 15 million child benefit records has brutally revealed the ease with which information can be transferred and lost. We have since had many positive comments about our advice to think carefully before downloading personal information to a government agency-run, centralised database. The frantic search through rubbish heaps for this information simply underlines the fact that once in the public domain, information will have a life of its own and cannot be controlled. The naive belief that simply returning information makes no difference to the damage done is perpetuated in government statements; in that context information loss is worse than theft.

But surely, safeguards are already in place to establish that medical information is more secure? After all, the 15 million records that were lost appeared to have been sent by a fairly junior member of staff; on the other hand it seems to have been sent in an easily readable and identifiable format on the basis of cost. The NHS may be no better; the decision to use a mailshot, rather than a personal letter was presumably based on cost. In 2005, a manager attached an Excel spreadsheet to a press release. This had the names, demographic data, and clinical details of 92 patients embedded in the information. ${ }^{5}$ It was explained that the manager was under great pressure to deliver a report to the health board in time for the positive press release, that they asked for information to be recalled and emails to be deleted. That's okay then. The manager had personal identifiable clinical information for audit; had copied it to a laptop; and taken it home; all errors repeated many times since.

In the US, already much more advanced than us about the use of IT in medical systems, a banker who sat on a state health commission accessed a list of people who had been diagnosed as having cancer and promptly called in their loans. ${ }^{6}$ Unfortunately, the only way to limit damage is to make information less easily available. On a more paranoid note, one IT expert has suggested 'One of my main privacy concerns at the moment is that the central computer system that records everybody's NHS number also contains a list of all the healthcare providers where you've been treated. Access to the NHS number system is likely to become widespread as it's much the most accurate and up-to-date population register in the UK. I expect that within 5 years, the NHS number database will be the principal method used by the police to trace people, and that private eyes will bribe their way in as well.'

It may well be that one of the consequences of this profligate information sharing is that many patients, for a number of reasons, will choose to have private care. As a consequence of that there will be no reliable record within the NHS system of that care, and many patients will have incomplete or absent information about care that would previously have been easily accessed by 
more traditional methods. But surely no government would want to encourage such a change? Most of the patients who opted out in our practice were intelligent, articulate, and could certainly afford some form of private insurance or private care. Might this become a control mechanism or encourage the private medical sector?

We can do better in future. It is time that we properly re-established our branch of the profession as independent of mind and deed; above all else focused on the rights and welfare of individuals. We need to ensure that the founding principle of an independent GP system is to defend the rights of the individual within a state system. We should not simply be an extension of an establishment which has seemed to become more interested in the workings of its own organisation than serving patients as individuals.

The development of this IT system is the pinnacle of 20 years work and persistent reform, enshrining three major principles; the triumph of process over outcome; the implementation of a solution that is looking for a problem; and the overriding of individual freedom and professional standards for management or political objectives.

We should reflect carefully on who is going to gain most from this information sharing. Patients who already receive an outstanding service? Doctors and other staff who provide an excellent service, who already communicate well in a wide variety of ways? Managers and politicians? Remember the poor soul who cried inconsolably in the surgery because a secret was out. The postman taught our community an indelible lesson about our unique and special relationship based on confidentiality. Who will teach the same lesson to the doctors in the global village?

\section{Gordon Baird}

\section{REFERENCES}

1. General Medical Council. Confidentiality: Protecting and Providing Information. http://www.gmcuk.org/guidance/current/library/confidentiality.asp (accessed 14 Jan 2008)

2. Scottish Consumer Council. Health on-line: public attitudes to data sharing in the NHS. http://www.scotconsumer.org.uk/publications/reports/ documents/rpllonline_sum.pdf (accessed 14 Jan 2008)

3. E-Health Insider Primary Care. RCGP ethics committee recommends opt-in for NCRS. http://www.ehiprimarycare.com/news/1489/rcgp_ethic s_committee_recommends_opt (accessed 14 Jan 2008).

4. Medical Defence Union. Update on NHS electronic summary care record in England.

http://www.ymcentre.freeserve.co.uk/download/MDU_ NCRS2.pdf (accessed 9 Jan 2008).

5. E-Health Insider Primary Care. PCT safety culture

needed to prevent errors.

www.ehiprimarycare.com/News/1458/pct_safety_cultu re_needed_to_prevent_errors (accessed 9 Jan 2008).

6. Anderson R. NHS-wide networking and patient confidentiality. BMJ 1995; 311(6996): 5 .

DOI: 10.3399/bjgp08X277131

\section{Further reading.}

- http://www.bma.org.uk/ap.nsf/Content/HSCresponseEPR

- www.rcgp.org.uk/pdf/confidentiality.pdf

- http://www.bbc.co.uk/devon/news/032002/06/confidential_files.shtml

Information about mentally ill patients was left on a computer loaned out to a former patient

- http://news.bbc.co.uk/1/hi/england/2836193.stm

A hospital has launched an investigation after a woman bought a computer chip which revealed cancer patients' medical records.

- http://news.bbc.co.uk/1/hi/england/hereford/worcs/3708758.stm

Computers containing patients' medical records have been taken in a break-in at a

Worcestershire medical centre.

- http://news.bbc.co.uk/1/hi/england/bristol/7119075.stm

An employer of a relatively small computer supplier to the NHS was looking up information about one of his relatives

- http://www.guardian.co.uk/technology/2005/jun/29/internet.epublic

More than three-quarters $(77 \%)$ of those surveyed on plans to introduce electronic healthcare records said healthcare professionals should seek patients' explicit consent before putting their records online.

- http://confidential.oxfordradcliffe.net/caldicott/report/recommendations

Caldicott Report

- http://www.scotland.gov.uk/Resource/Doc/143714/0036499.pdf

(The leaflet - Emergency Care Summary)

- http://www.bma.org.uk/ap.nsf/Content/manifestobriefingconfidentiality?OpenDocument\&

Highlight=2, confidentiality

(Scotland BMA stating that there is a need to inform the public about computer recording on a central database)

- http://www.bma.org.uk/ap.nsf/Content/PatientConfidentialityguidelines

BMA guidelines - Medical confidentiality has never been absolute but has operated on a principle of limiting disclosure to those who need to know, giving them only and as much information as they need. This general rule is waived where, for example, a breach of confidence is required by law or where the patient gives valid consent.

Valid or real consent is that which is freely given, based upon a real understanding of the issues involved. Patients need to know what information will be divulged, who to and how far the recipients will have any obligation of confidentiality before spreading the information more widely. They should be asked specifically to agree to the use of their clinical information in the different investigative and complaints processes.

- http://www.bma.org.uk/ap.nsf/Content/ConfidentialityBiggerPicture

The BMA currently advises that legally and ethically health professionals are responsible to patients for the confidentiality of the health information they hold. When they provide information, patients imply consent to some sharing with other healthcare professionals. There should be no use or disclosure of any confidential patient identifiable information gained in the course of professional work for any purpose other than the clinical care of the patient to whom it relates. There are three broad exceptions to this standard:

- where there is consent;

- where the law requires disclosure; or

- where there is an overriding public interest in disclosure.

This document also states: 'With a move away from this vision of a personalised one-to-one health service, it is arguable whether the concept of a traditional confidentiality-based relationship is sustainable.'

- http://www.gmc-uk.org/guidance/current/library/confidentiality.asp\#1

If you are asked to provide information about patients you must: inform patients about the disclosure, or check that they have already received information about it.

- http://www.connectingforhealth.nhs.uk/ 